\title{
Adrenergically Mediated Intrapancreatic Control of the Glucagon Response to Glucopenia in the Isolated Rat Pancreas
}

\author{
A. Hisatomi, H. Maruyama, L. Orci, M. Vasko, and R. H. Unger \\ Veterans Administration Medical Center and The University of Texas Health Science Center, Dallas, Texas 75216; \\ and The University of Geneva School of Medicine, Geneva, Switzerland
}

\begin{abstract}
Alpha adrenergic blockade with phentolamine $(10 \mu \mathrm{M})$ reduces the glucagon response to severe glucopenia (from 150 to 25 $\mathrm{mg} / \mathrm{dl})$ to $22 \%$ of the control values in the isolated perfused rat pancreas. Propranolol (10 $\mu \mathrm{M})$ had no significant effect. Neither alpha nor beta adrenergic blockade reduced the magnitude of glucopenic suppression of insulin secretion, but phentolamine increased insulin levels before and during glucopenia. The pattern of somatostatin secretion in these experiments resembled that of insulin. Depletion of norepinephrine from sympathetic nerve endings by pretreatment with 6-hydroxydopamine lowered the pancreatic norepinephrine content to less than $20 \%$ of control values and reduced the glucagon response to glucopenia to $69 \%$ of the controls.

Combined alpha and beta adrenergic blockade during less severe glucopenia (from 120 to $60 \mathrm{mg} / \mathrm{dl}$ ) reduced the glucagon response to $21 \%$ of controls. However, slight glucopenia (from 100 to $80 \mathrm{mg} / \mathrm{dl}$ ), which elicited only $11 \%$ increase in glucagon in the control experiments, was not altered significantly by combined alpha and beta adrenergic blockade. Morphologic studies of adrenergic nerve terminals labeled with [ ${ }^{3} \mathrm{H}$ ]norepinephrine revealed associations with alpha cells.

It is concluded that in the isolated rat pancreas adrenergic mediation accounts for most of the glucagon but not insulin response to glucopenia. It is controlled within the pancreas itself, possibly through a direct enhancement by glucopenia of norepinephrine release from nerve endings.
\end{abstract}

\section{Introduction}

Increased glucagon secretion normally constitutes an important component of the vital defense against glucopenia $(1,2)$, but the mechanism of this response is unclear. Adrenergic mediation is suggested by the facts that infusion of catecholamines (3-6), stimulation of the sympathetic nerves to the pancreas (7-9) and stimulation of the ventral medial nucleus of the hypothalamus (10) all increase glucagon secretion, and that glucopenia stimulates glucagon and norepinephrine release from the isolated canine pancreas (11). Nevertheless, in man adrenergic blockade has not been found to reduce the glucagon response to hypoglycemia (12).

This work was presented in part at the 44th Annual Meeting of the American Diabetes Association, June, 1984, in Las Vegas, Nevada.

Dr. Unger is a Senior Medical Investigator, Dallas VA Medical Center. Address reprint requests to Dr. Unger.

Received for publication 25 June 1984 and in revised form 27 September 1984.

The Journal of Clinical Investigation, Inc.

Volume 75, February 1985, 420-426
In this report we present evidence that in the rat the glucagon response to glucopenia is to a large extent adrenergically mediated and that its control is via local intrapancreatic control rather than through the central nervous system.

\section{Methods}

Perfusion experiments. The pancreata of male Long-Evans rats were isolated and perfused using the system of Grodsky and Fanska (13). After a 27-30-h fast, the rats were anesthetized with $50 \mathrm{mg} / \mathrm{kg}$ of sodium pentobarbital injected intraperitoneally. $15 \mathrm{~min}$ later the pancreas with an adjacent $5-\mathrm{cm}$ portion of the duodenum was isolated and transferred within $35-40 \mathrm{~min}$ to a thermostatically controlled plexiglas perfusion chamber in which the celiac trunk and the portal vein were cannulated. With the external surface temperature of the pancreas maintained between 37.0 and $37.5^{\circ} \mathrm{C}$, nonrecirculating perfusion was begun at a constant flow rate of $3.6 \mathrm{ml} / \mathrm{min}$ using a KrebsRinger bicarbonate buffer supplemented with $4.5 \%$ (wt/vol) of dextranT-70, 1\% (wt/vol) of bovine serum albumin (A-5128, Sigma Chemical Co., St. Louis, MO), $10 \mathrm{mmol}$ arginine, $5 \mathrm{mmol}$ sodium pyruvate, sodium fumarate, and sodium glutamate. The $\mathrm{PO}_{2}$ was maintained between 450 and $550 \mathrm{~mm} \mathrm{Hg}$ by bubble oxygenator using a gas mixture of $95 \% \mathrm{O}_{2}$ and $5 \% \mathrm{CO}_{2}$. The perfusate $\mathrm{pH}$ was maintained between 7.35 and 7.45. In these experiments the glucose concentration was either 150,120 , or $100 \mathrm{mg} / \mathrm{dl}$ for the first and last $10 \mathrm{~min}$ of the perfusion and the concentration was 25,60 , or $80 \mathrm{mg} / \mathrm{dl}$, respectively, during the intervening $15 \mathrm{~min}$ of the 35 -min experiments. In half of the experiments $10 \mu \mathrm{M}$ phentolamine and/or $10 \mu \mathrm{M}$ propanolol was present in the perfusate throughout the entire experiment. A 10-min equilibration period preceded each experiment.

In one group of perfusion experiments the pancreas was obtained from rats pretreated with 50 or $75 \mathrm{mg} / \mathrm{kg}$ of 6-hydroxydopamine administered intravenously on two occasions $48 \mathrm{~h}$ apart. Experiments were conducted 3-5 d after the second injection.

Insulin was measured by the Herbert modification (14) of the method of Yalow and Berson (15). Glucagon was measured by a previously described method using antiserum 30K (16). Somatostatin was measured by the method of Vasquez et al. (17).

Determination of norepinephrine content of pancreas. Norepinephrine content was determined by a modification of the method of Refshauge et al. (18). After perfusion was complete, pancreata were weighed and homogenized in $5 \mathrm{ml}$ of $0.1 \mathrm{M} \mathrm{HClO}_{4}$ containing dihydroxybenzylamine $(100 \mathrm{ng})$ as the internal standard and then centrifuged at $3,000 \mathrm{~g}$ for $15 \mathrm{~min}$ at $4^{\circ} \mathrm{C}$. The supernatant was transferred to clean test tubes

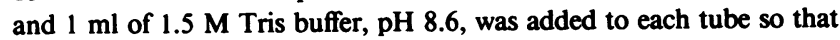
the final $\mathrm{pH}$ of the supernatant was between 7.5 and 8.0. The sample was mixed and $75 \mathrm{mg}$ of activated alumina was added to each tube. After thorough mixing, the samples were centrifuged at $3,000 \mathrm{~g}$ for 15 min and the supernatant was discarded by decanting. The alumina was resuspended in $2 \mathrm{ml}$ of deionized distilled water and again centrifuged at $3,000 \mathrm{~g}$ for $15 \mathrm{~min}$. The water was removed and the alumina resuspended in $100 \mu \mathrm{l}$ of $0.4 \mathrm{M} \mathrm{HClO}_{4}$ by mixing for $40 \mathrm{~s}$. The sample was again centrifuged at $3,000 \mathrm{~g}$ for $15 \mathrm{~min}$. The supernatant was removed and frozen until assay (2-3 d). Catecholamines were assayed by high pressure liquid chromatography. $10 \mu \mathrm{l}$ of the sample containing catecholamines was injected onto a $25 \times 4-\mathrm{cm}$ reverse- 
phase column (chromasorb C-18, Waters Associates, Milford, MA). The mobile phase used consisted of $0.1 \mathrm{M}$ citric acid, $0.1 \mathrm{M} \mathrm{Na}_{2} \mathrm{HPO}_{4}$ (pH 3.0), $1 \mathrm{mM}$ EDTA, $0.6 \mathrm{mM}$ sodium octyl sulfate, $10 \%$ methanol with a flow rate of $2 \mathrm{ml} / \mathrm{min}$. Catecholamines were detected electrochemically using a glassy carbon electrode at oxidation potential of $0.55 \mathrm{~V}$ against a reference $\mathrm{Ag} / \mathrm{AgCl}$ electrode. Norepinephrine concentrations were determined as the ratio of the area under the unknown peak to the area of the internal standard peak and compared to a standard curve.

All data were expressed as mean \pm SEM. Statistical differences were determined by the Student $t$ test for two groups.

Morphologic studies. A normal albino rat (body weight $100 \mathrm{~g}$ ) was injected intraperitoneally with $1.0 \mathrm{mCi}\left[{ }^{3} \mathrm{H}\right]$ norepinephrine (sp act $36.8 \mathrm{Ci} / \mathrm{mmol}$; Amersham Ltd., Buckinghamshire, England). After 1 $\mathrm{h}$ the animal was fixed by perfusion through the left ventricle with $1 \%$ glutaraldehyde plus $1 \%$ paraformaldehyde in $0.1 \mathrm{M}$ phosphate buffer (pH 7.4). The splenic portion of the pancreas was dissected, postfixed in osmium tetroxide and autoradiographed using Ilford L4 emulsion (19). Exposure time was 4 wk. The emulsion was developed with Microdol X (Eastman Kodak Co., Rochester, NY).

\section{Results}

Effect of alpha and beta adrenergic blockade on the glucagon, insulin, and somatostatin response to hypoglycemia. In eight control experiments, a decline in perfusate glucose concentration from 150 to $25 \mathrm{mg} / \mathrm{dl}$ elicited a rise in mean glucagon levels to a peak more than three times the base-line levels within $3 \mathrm{~min}$ after the start of the glucopenic period. Glucagon levels remained elevated throughout the glucopenic period and returned promptly to base-line levels when the glucose level was restored to the initial value (Fig. $1 A$; Table I). Alpha adrenergic blockade with phentolamine $(10 \mu \mathrm{M})$ reduced the response to glucopenia to $22 \%$ of control values (Fig. $1 \mathrm{~A}$ and Table I). Propanolol $(10 \mu \mathrm{M})$ had no significant effect.

Glucopenia suppressed insulin secretion in the normal rat pancreas from a mean baseline above $300 \mu \mathrm{U} / \mathrm{ml}$ to $\sim 20 \mu \mathrm{U} /$ $\mathrm{ml}$ during the period of glucopenia (Fig. $1 B$; Table II). Alpha adrenergic blockade with phentolamine significantly increased base-line insulin values but did not reduce the magnitude of insulin suppression by glucopenia (Fig. $1 B$ ). In fact, apparent enhancement of glucopenic suppression of insulin secretion was observed in the phentolamine perfusion experiments (Table II), although the difference in baselines makes such an interpretation questionable. However, even when maximally suppressed, the minimal level of insulin secretion during adrenergic blockade was five times that of control experiments. Propranolol also caused a significant elevation in the base-line insulin values but did not alter the magnitude of insulin suppression. Interestingly, a significant increase in insulin was observed during propranolol perfusion during glucopenia. The augmented glucopenic suppression of insulin secretion in these experiments would appear to be secondary to the striking elevation of the baseline.

Somatostatin was also measured in these experiments to determine if reduction in glucopenia-induced glucagon secretion by phentolamine might be secondary to diminished suppression of D-cell secretion. Phentolamine did not reduce the magnitude of the suppression of somatostatin by glucopenia (Fig. 2). As in the case of insulin, the base-line levels of somatostatin were higher during phentolamine perfusion (Fig. 2) and the minimal rate of somatostatin secretion during suppression remained higher than that of the controls.
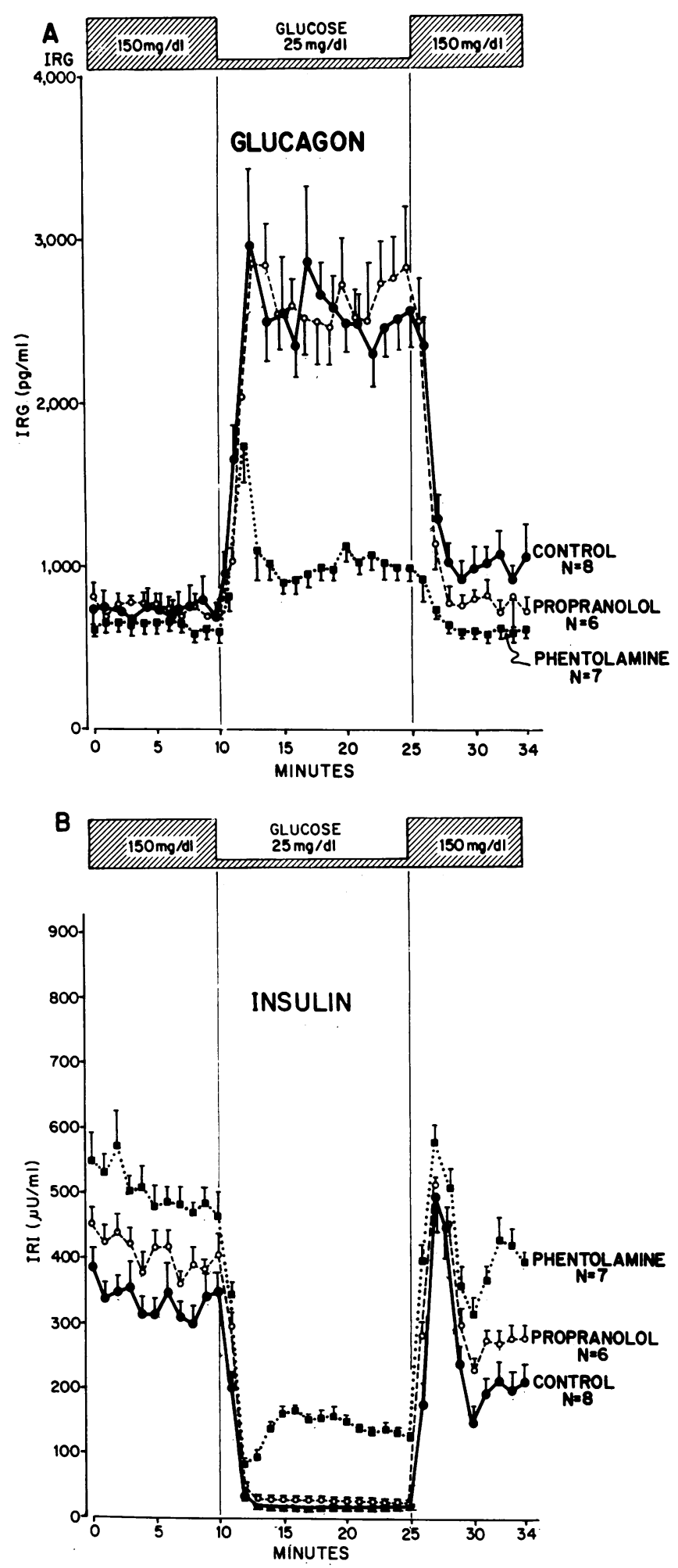

Figure 1. $(A)$ The effect of alpha- and beta-adrenergic blockade on the glucagon response to severe glucopenia in the isolated rat pancreas. $(B)$ The insulin response in the same experiments.

Effect of 6-hydroxydopamine pretreatment with and without alpha adrenergic blockade on the glucagon and insulin response to glucopenia. To test further whether the glucagon response to glucopenia is adrenergically mediated, pancreata of rats pretreated with 6-hydroxydopamine were perfused at glucose 
Table I. Glucagon Response to Glucopenia* During Alpha and Beta Adrenergic Blockade and Following 6-Hydroxydopamine Pretreatment in Isolated Pancreata of Rats

\begin{tabular}{|c|c|c|c|c|c|c|}
\hline & \multicolumn{6}{|l|}{ IRG } \\
\hline & $\begin{array}{l}\text { Basal secretion } \\
\text { rate }\end{array}$ & Maximal secretion & $P$ valueł & Change & $P$ value§ & \\
\hline & $n g / \min$ & $n g / \min$ & & $n g / \min$ & & $\%$ \\
\hline \multicolumn{7}{|l|}{$\mathrm{G} 150 \rightarrow 25$} \\
\hline Control (8) & $2.90 \pm 0.40$ & $9.41 \pm 0.77$ & - & $6.51 \pm 0.47$ & - & 100.0 \\
\hline Phentolamine (7) & $2.52 \pm 0.18$ & $3.96 \pm 0.28$ & $<0.001$ & $1.45 \pm 0.18$ & $<0.001$ & 22.3 \\
\hline Propranolol (6) & $2.97 \pm 0.27$ & $10.33 \pm 0.83$ & NS & $7.35 \pm 0.61$ & NS & 112.9 \\
\hline Phentolamine + Propranolol (8) & $2.93 \pm 0.30$ & $5.48 \pm 0.58$ & $<0.01$ & $2.56 \pm 0.34$ & $<0.001$ & 39.3 \\
\hline 6OH Dopamine (10) & $2.28 \pm 0.17$ & $6.77 \pm 0.39$ & $<0.01$ & $4.49 \pm 0.27$ & $<0.01$ & 69.0 \\
\hline $6 \mathrm{OH}$ Dopamine + Phentolamine (5) & $1.90 \pm 0.19$ & $2.76 \pm 0.17$ & $<0.001$ & $0.86 \pm 0.21$ & $<0.001$ & 13.2 \\
\hline \multicolumn{7}{|l|}{$\mathrm{G} 120 \rightarrow 60$} \\
\hline Control (8) & $3.64 \pm 0.51$ & $8.35 \pm 1.10$ & - & $4.71 \pm 0.72$ & - & 100.0 \\
\hline Phentolamine + Propranolol (9) & $2.64 \pm 0.21$ & $3.74 \pm 0.24$ & $<0.001$ & $1.10 \pm 0.06$ & $<0.001$ & 21.4 \\
\hline \multicolumn{7}{|l|}{$\mathrm{G} 100 \rightarrow 80$} \\
\hline Control (5) & $2.72 \pm 0.25$ & $3.03 \pm 0.21$ & - & $0.30 \pm 0.08$ & - & 100.0 \\
\hline Phentolamine + Propranolol (6) & $3.10 \pm 0.26$ & $3.29 \pm 0.42$ & NS & $0.19 \pm 0.22$ & NS & 63.3 \\
\hline
\end{tabular}

* 150-25-150 mg/dl. $\ddagger$ Versus maximal secretion rate in control experiments. § Versus change in control experiments.

concentrations of $150-25-150 \mathrm{mg} / \mathrm{dl}$. Their norepinephrine content determined after perfusion averaged $91 \pm 11 \mathrm{ng} / \mathrm{g}$ wet wt, significantly below that of control rats $(555 \pm 45 \mathrm{ng} / \mathrm{g} ; P$ $<0.001$ ). Their glucagon response to glucopenia (Fig. $3 A$ ) was reduced to $69 \%$ of controls $(P<0.01)$ (Fig. $3 A$; Table I) and was significantly greater than that induced in normal rat pancreata by combined alpha and beta adrenergic blockade ( $P$ $<0.001$ ) (Fig. $3 A$; Table I). Phentolamine perfusion of pancreata from the 6-hydroxydopamine-pretreated rats lowered the glucagon response to $13 \%$ of controls but did not completely abolish it (Fig. 3 A; Table I).

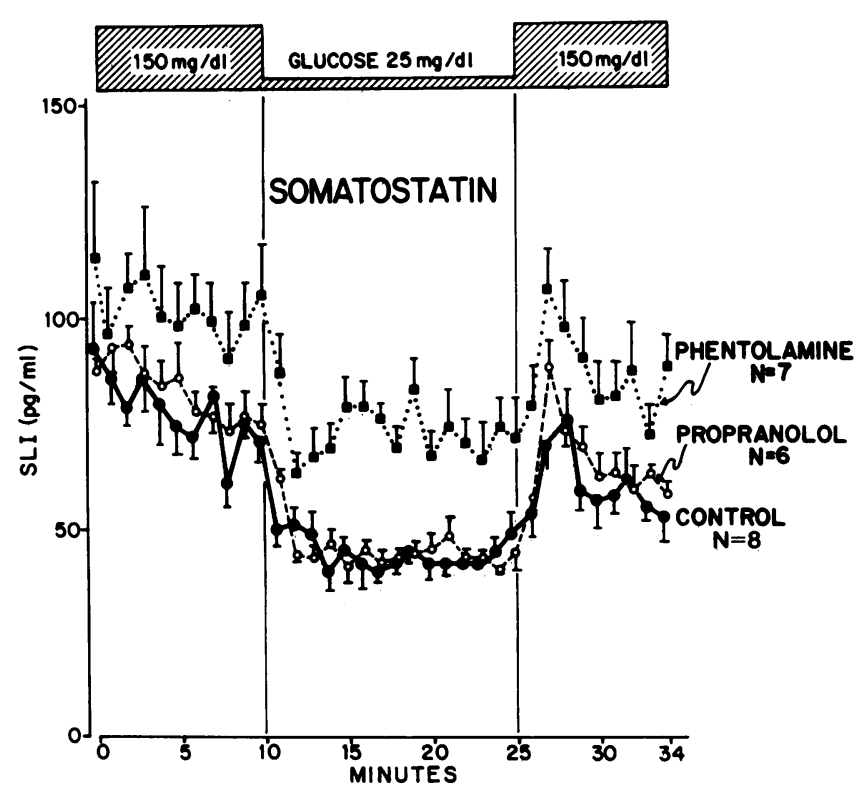

Figure 2. The effect of alpha and beta adrenergic blockade on the somatostatin (SLI) response to glucopenia in the isolated rat pancreas.
Pretreatment with 6-hydroxydopamine reduced the baseline insulin levels but in contrast to the effects of the adrenergic blockers did not prevent complete suppression by glucopenia (Fig. $3 \mathrm{~B}$; Table II). Phentolamine raised the base-line in 6hydroxydopamine-pretreated pancreata, as did combined phentolamine-propranolol perfusion of normal pancreata, but did not reduce glucopenic suppression of insulin secretion (Table II; Fig. 3 B).

Effect of adrenergic blockade on the glucagon and insulin response to less severe glucopenia. To determine if adrenergic mechanisms are involved in the glucagon response to less severe declines in glucose, pancreata were perfused at glucose concentrations of 120-60-120 ng/dl and 100-80-100 mg/dl. In the control experiments the decline from 120 to $60 \mathrm{mg} / \mathrm{dl}$ elicited a doubling of glucagon secretion (Fig. $4 \mathrm{~A}$ ). Combined alpha and beta blockade reduced the glucagon response to $21 \%$ of the controls.

By contrast, a decline in glucose from 100 to $80 \mathrm{mg} / \mathrm{dl}$ elicited a rise of only $11 \%$ in glucagon secretion in the control experiments. This small change, which was not statistically significant, was not influenced by combined alpha and beta adrenergic blockade (Fig. $5 \mathrm{~A}$ ).

Insulin levels during combined alpha and beta adrenergic blockade were elevated both during the base-line period and during glucopenic suppression but the magnitude of insulin suppression during moderate or slight glucopenia was not reduced (Figs. $4 B$ and $5 B$ ).

Morphologic studies. To gain insight into the morphologic relationships between adrenergic nerve endings and islet cells, the adrenergic nerve terminals of a normal albino rat were labeled with $\left[{ }^{3} \mathrm{H}\right]$ norepinephrine and sections of 10 islets were examined. 93 nerve terminals were in direct apposition with endocrine cells; of the 93 terminals, 34 were in contact with glucagon-containing cells (Fig. 6), 55 with insulin cells, 2 with somatostatin cells, and 2 with PP cells. If these contacts are related to the previously determined numbers of $B$ and non-B 

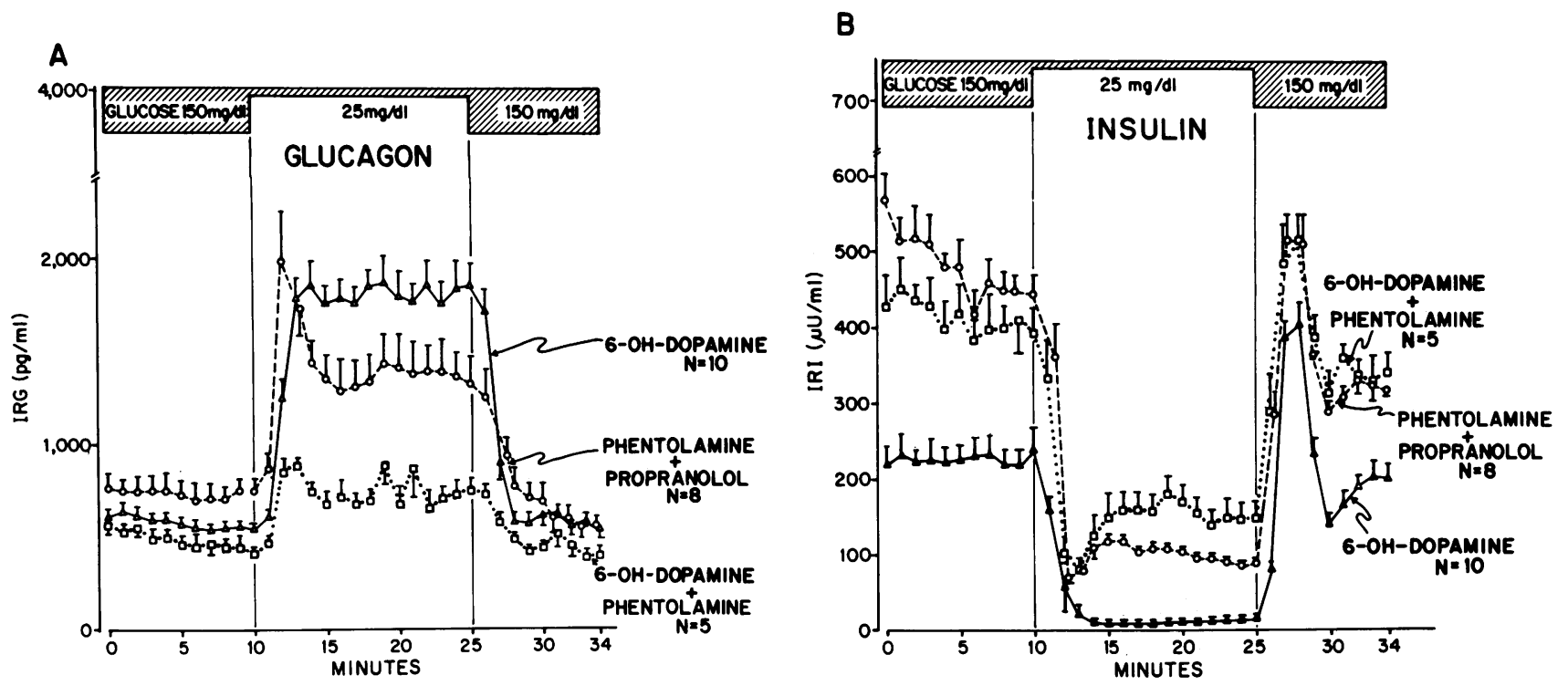

Figure 3. $(A)$ Comparison of the glucagon response of the rat pancreas isolated from normal rats and perfused with phentolamine plus propranolol and from rats pretreated with 6-hydroxydopamine (6-OH-dopamine) and perfused with and without phentolamine. (B) The insulin response in the same experiments.

cells in a rat splenic islet (20) one obtains a ratio of $55 / 2063$ $(=0.026)$ and $38 / 1063(=0.035)$, respectively.

\section{Discussion}

Alpha adrenergic blockade and 6-hydroxydopamine pretreatment significantly reduce the glucagon response to glucopenia in the isolated rat pancreas. This demonstrates the existence of an adrenergically mediated glucagon response to hypoglycemia in the rat, and indicates that glucagon release can be regulated from within the pancreas rather than from regions in the hypothalamus or elsewhere in the central nervous system. Alpha adrenergic blockade reduced glucagon secretion in response both to a profound reduction of glucose concen- tration from 150 to $25 \mathrm{mg} / \mathrm{dl}$ and to a moderate reduction from 120 to $60 \mathrm{mg} / \mathrm{dl}$. However, it did not significantly alter the small glucagon response to a change in glucose concentration from 100 to $80 \mathrm{mg} / \mathrm{dl}$, suggesting that the alpha adrenergic influence over glucagon secretion may not be important when the decline in glucose concentration is small and within the normal range of physiologic variation.

No comparable evidence of local intrapancreatic alpha adrenergic control of the insulin response to glucopenia was obtained. Base-line insulin levels were significantly increased by phentolamine and to a lesser degree by propanolol infusion, as earlier work had demonstrated $(6,21)$, but there was no clear reduction in the magnitude of glucopenic suppression of insulin secretion during adrenergic blockade.

Table II. Insulin Response to Glucopenia* During Alpha and Beta Adrenergic Blockade and Following 6-Hydroxydopamine Pretreatment in Isolated Pancreata of Rats

\begin{tabular}{|c|c|c|c|c|c|c|}
\hline & \multicolumn{6}{|l|}{ IRI } \\
\hline & $\begin{array}{l}\text { Basal secretion } \\
\text { rate }\end{array}$ & Minimal secretion & $P$ valueł & Change & $P$ value $\S$ & \\
\hline & $\mu \mathrm{m} / \mathrm{min}$ & $\mu \mathrm{m} / \mathrm{min}$ & & $\mu \mathrm{m} / \mathrm{min}$ & & $\%$ \\
\hline \multicolumn{7}{|l|}{$\mathrm{G} 150 \rightarrow 25$} \\
\hline Control (8) & $1.32 \pm 0.09$ & $0.12 \pm 0.02$ & - & $1.20 \pm 0.08$ & - & 100.0 \\
\hline Phentolamine (7) & $2.01 \pm 0.07$ & $0.59 \pm 0.03$ & $<0.001$ & $1.42 \pm 0.06$ & NS & 118.3 \\
\hline Propranolol (6) & $1.62 \pm 0.07$ & $0.19 \pm 0.02$ & $<0.05$ & $1.43 \pm 0.06$ & NS & 119.2 \\
\hline Phentolamine + Propranolol (8) & $2.01 \pm 0.13$ & $0.49 \pm 0.04$ & $<0.001$ & $1.52 \pm 0.09$ & $<0.05$ & 126.6 \\
\hline 6OH Dopamine (5) & $0.90 \pm 0.08$ & $0.09 \pm 0.02$ & NS & $0.81 \pm 0.07$ & $<0.01$ & 67.5 \\
\hline $6 \mathrm{OH}$ Dopamine + Phentolamine $(5)$ & $1.64 \pm 0.13$ & $0.62 \pm 0.09$ & $<0.001$ & $1.02 \pm 0.09$ & NS & 85.0 \\
\hline \multicolumn{7}{|l|}{$\mathrm{G} 120 \rightarrow 60$} \\
\hline Control (8) & $0.82 \pm 0.13$ & $0.11 \pm 0.02$ & - & $0.71 \pm 0.11$ & - & 100.0 \\
\hline Phentolamine + Propranolol (9) & $1.54 \pm 0.13$ & $0.44 \pm 0.04$ & $<0.001$ & $1.10 \pm 0.10$ & $<0.05$ & 154.9 \\
\hline \multicolumn{7}{|l|}{$\mathrm{G} 100 \rightarrow 80$} \\
\hline Control (5) & $0.36 \pm 0.05$ & $0.15 \pm 0.03$ & - & $0.21 \pm 0.03$ & - & 100.0 \\
\hline Phentolamine + Propranolol (6) & $1.22 \pm 0.09$ & $0.74 \pm 0.04$ & $<0.001$ & $0.48 \pm 0.06$ & $<0.01$ & 228.6 \\
\hline
\end{tabular}

* $150-25-150 \mathrm{mg} / \mathrm{dl}$. $¥$ Versus minimal secretion rate in controls. $\S$ Versus change in controls. 
A

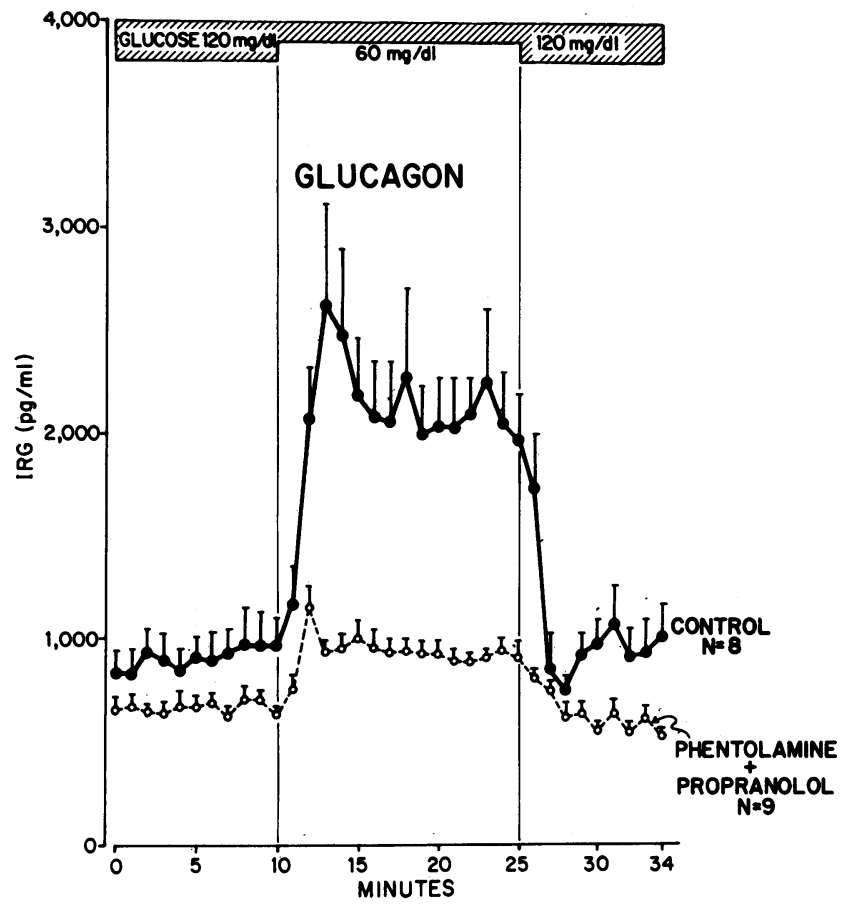

B

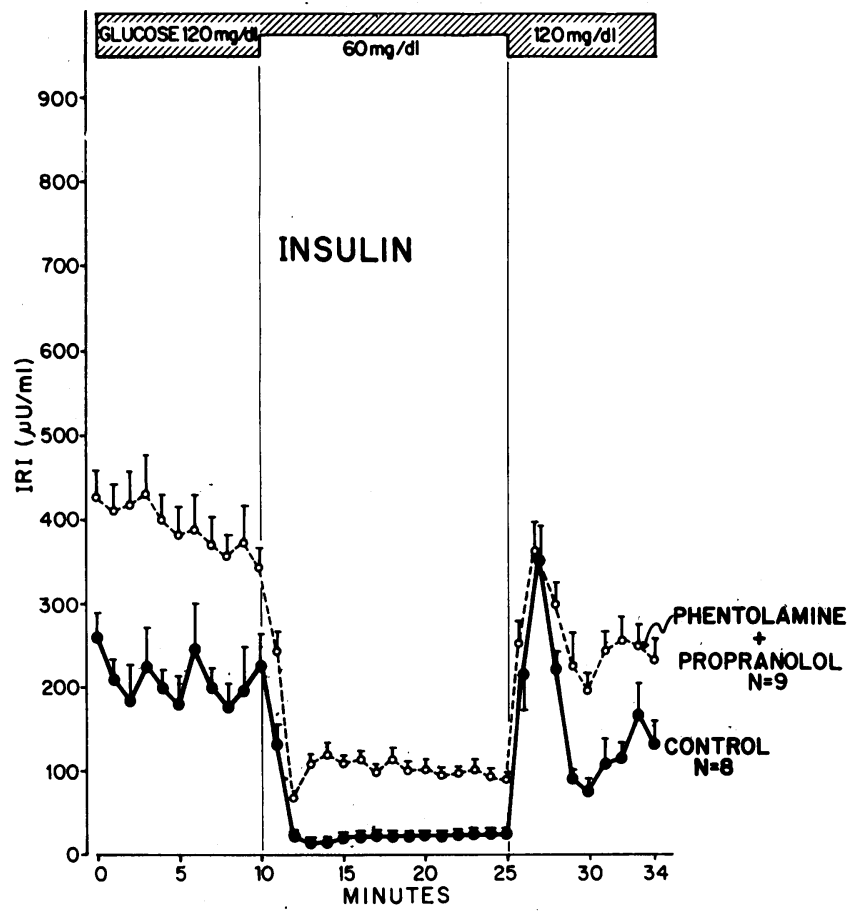

Figure 4. $(A)$ The effect of combined phentolamine and propranolol perfusion upon the glucagon response to moderate glucopenia. The adrenergic blockers were perfused throughout the experiment. $(B)$ The insulin response in the same experiments.

Neither the site nor the mechanism of intrapancreatic adrenergic control of glucagon secretion was determined in these studies. Perhaps glucopenia provokes a local release of norepinephrine from sympathetic nerve endings of the islets and this provides the major stimulus to glucagon secretion during severe and moderate glucopenia. Indeed, glucose deprivation causes a significant increase in release of both norepinephrine and glucagon in the isolated canine pancreas
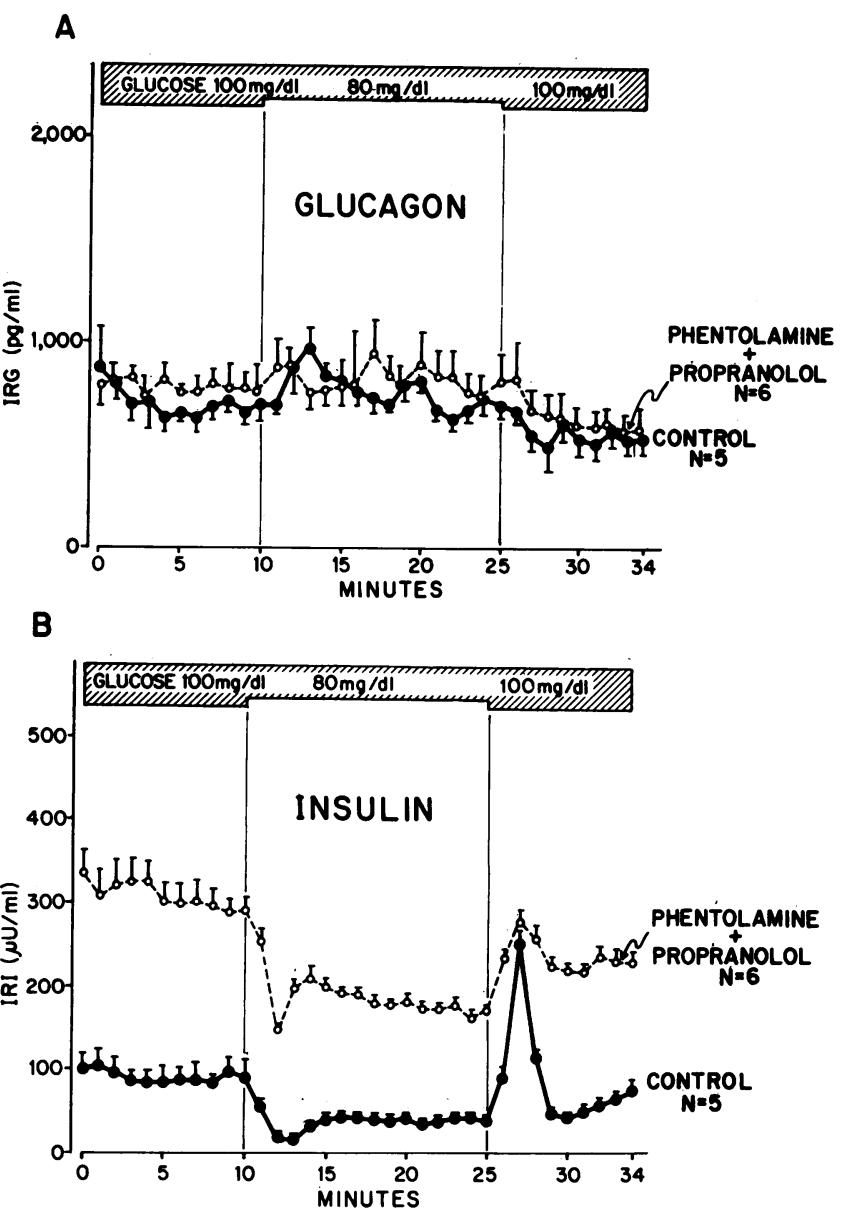

Figure 5. (A) The effect of combined phentolamine-propranolol perfusion on the glucagon response to slight glucopenia. $(B)$ The insulin response in the same experiments.

(11). In addition, the demonstration of adrenergic nerve endings in contact with glucagon-secreting cells, which confirms earlier studies (22), provides an anatomical basis for a functional relationship. However, there was no clearcut morphologic evidence of preferential innervation of glucagon cells relative to insulin cells to account for the more profound influence of adrenergic blockade on glucagon secretion.

The persistance of $22 \%$ of the glucagon response to glucopenia despite adrenergic blockade was not explained by these studies. Perhaps the adrenergic blockade was not complete or non-adrenergic neurotransmitters played a role. Other mediating factors such as a direct effect of glucopenia or higher levels of insulin and/or somatostatin during the adrenergic blockade might also explain the results. The magnitude of insulin and somatostatin suppression was not diminished by adrenergic blockade, but the absolute levels of both hormones were higher.

Depletion of norepinephrine stores in sympathetic nerve endings by pretreatment with 6-hydroxydopamine reduced pancreatic norepinephrine content to $16 \%$ of the control rats, while the glucagon response of such pancreata to glucopenia was reduced to only $69 \%$ of controls. The apparent discrepancy may reflect the fact that the islets constitute only a small fraction of total pancreatic tissue receiving sympathetic innervation. Alternatively, the sensitivity of $A$ cells to residual norepinephrine might have increased as a consequence of depletion of the neurotransmitter. 


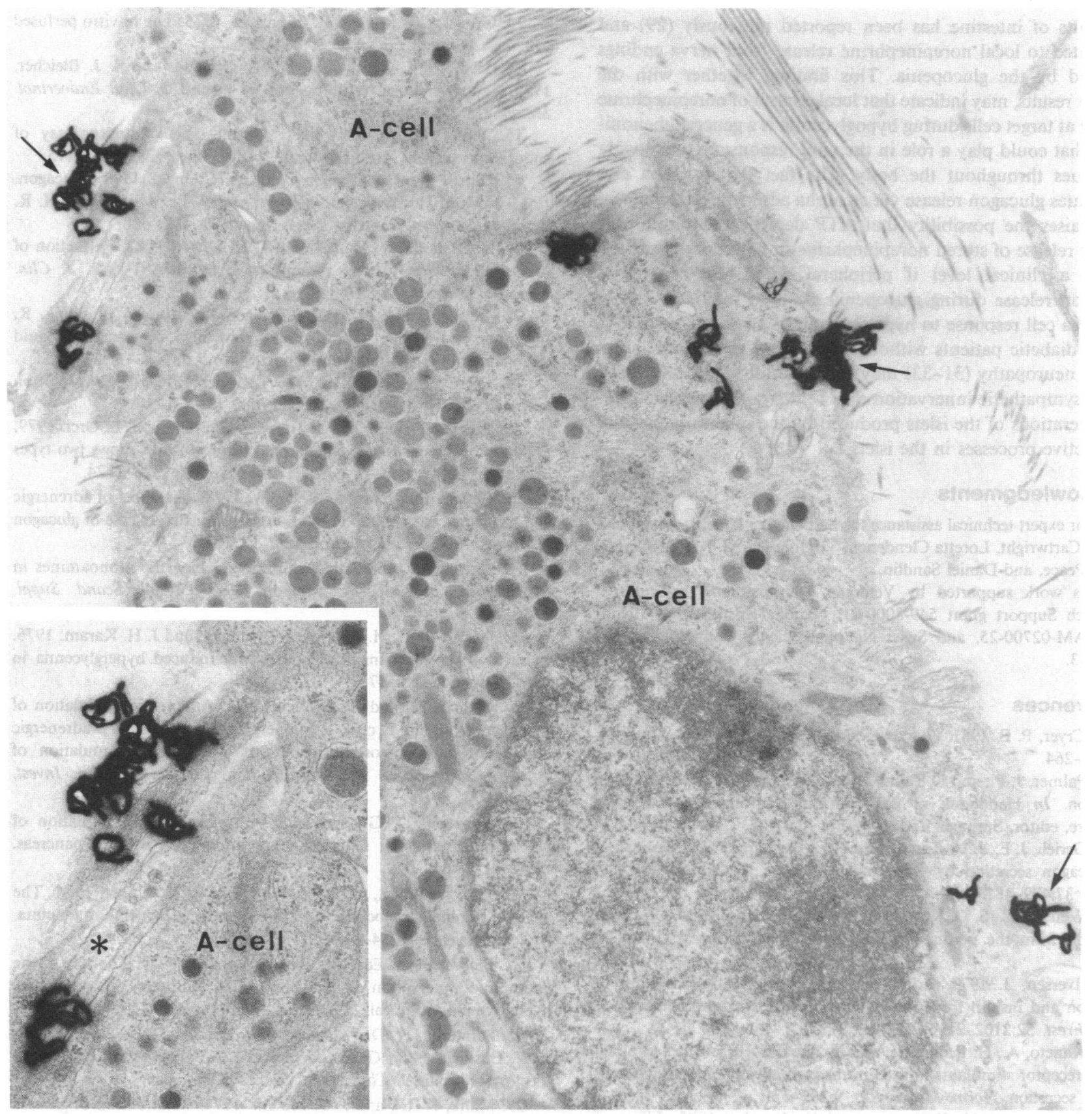

Figure 6. Example of electron microscope autoradiography showing several labeled nerve terminals (arrows) located at the periphery of a cluster of glucagon-containing cells (A-cells) in a rat islet. The inset

Although in man (23) and in dogs (5) the glucagon response to catecholamines appears to be mediated via beta adrenergic receptor activation, in rats the alpha receptor appears to be operative. Recent studies also suggest an alpha adrenergic effect in dogs (24). The glucagon response to scorpion toxin, a potent stimulus of norepinephrine release from nerve endings, is blocked in the isolated rat pancreas by the alpha blockers phentolamine and phenoxybenzamine (25), as is the glucagon response to exercise (26). The 6-hydroxydopamine experiments suggest that the phentolamine effects on glucagon secretion represent true alpha adrenergic blockade rather than some unidentified effect of the agent.

If these findings are applicable to other species, their implications may be substantial. The demonstration of a shows at higher magnification a labeled adrenergic nerve terminal (asterisk) in direct contact with an A-cell. $\times 12,000$; inset: $\times 21,000$.

locally controlled glucopenia-responsive adrenergic system in the pancreas would explain the failure of splanchnic nerve section in the calf (27) and cervical cord transection in man (28) to prevent the glucopenic glucagon response. The failure of adrenergic blocking agents to reduce the glucagon response to hypoglycemia in man might reflect the fact that an intravenous infusion of phentolamine in man at a rate of $5 \mu \mathrm{M}$ / min would deliver to the islets a concentration far below the $10-\mu \mathrm{M}$ concentration of phentolamine perfused directly into the rat pancreata. Alternatively, species differences might explain the discrepancy.

The current findings may also have certain physiologic implications extending beyond the islets. Vasoconstriction of mesenteric vessels during glucopenic perfusion of isolated 
segments of intestine has been reported previously (29) and attributed to local norepinephrine release from nerve endings induced by the glucopenia. This finding, together with the present results, may indicate that local control of norepinephrine release at target cells during hypoglycemia is a general phenomenon that could play a role in the vital response to glucopenia of tissues throughout the body. The fact that hypoxia also stimulates glucagon release via an alpha adrenergic mechanism (30), raises the possibility that ATP depletion is responsible for the release of stored norepinephrine in both circumstances.

At a clinical level if peripheral adrenergic control of glucagon release during glucopenia exists in man, the loss of an alpha cell response to hypoglycemia frequently observed in type I diabetic patients without evidence of generalized autonomic neuropathy (31-33) may be the result of a local change in the sympathetic innervation of A cells secondary to anatomical alterations of the islets produced by the inflammatory and destructive processes in the islets.

\section{Acknowledgments}

For their expert technical assistance the authors thank Helen Ausbrooks, Sherill Cartwright, Loretta Clendenen, Virginia Harris, Kay McCorkle, Lovie Peace, and Daniel Sandlin.

This work supported by Veterans Administration Institutional Research Support grant 549-8000-01, National Institutes of Health grant AM-02700-25, and Swiss National Science Foundation grant 3.460.83.

\section{References}

1. Cryer, P. E. 1981. Glucose counterregulation in man. Diabetes. 30:261-264.

2. Palmer, J. P., and D. Porte, Jr. 1983. Neural control of glucagon secretion. In Handbook of Experimental Pharmacology 66/II. P. Lefebvre, editor. Springer-Verlag, Berlin. 115-132.

3. Gerich, J. E., J. H. Karam, and P. H. Forsham. 1973. Stimulation of glucagon secretion by epinephrine in man. J. Clin. Endocrinol. Metab. 37:479-481.

4. Weir, G. C., S. D. Knowlton, and D. B. Martin. 1974. Glucagon secretion from the perfused rat pancreas. J. Clin. Invest. 54:14031412.

5. Iversen, J. 1973. Adrenergic receptors and the secretion of glucagon and insulin from the isolated, perfused canine pancreas. $J$. Clin. Invest. 52:2102-2116.

6. Kaneto, A., H. Kajinuma, and K. Kosaka. 1977. Effect of alpha adrenoreceptor stimulants infused intrapancreatically on glucagon and insulin secretion. Horm. Metab. Res. 9:267-271.

7. Kaneto, A., H. Kajinuma, and K. Kosaka. 1975. Effect of splanchnic nerve stimulation on glucagon and insulin output in the dog. Endocrinology. 96:143-150.

8. Bloom, S. R., and A. V. Edwards. 1975. The release of pancreatic glucagon and inhibition of insulin in response to stimulation of the sympathetic innervation. J. Physiol. 253:157-173.

9. Girardier, L., J. Seydoux, and L. A. Campfield. 1976. Control of $A$ and $B$ cells in vivo by sympathetic nervous input and selective hyper- or hypoglycemia in dog pancreas. J. Physiol. (Paris). 72:801814.

10. Frohman, L. A., and L. L. Bernardis. 1971. Effect of hypothalmic stimulation on plasma glucose, insulin and glucagon levels. Am. J. Physiol. 221:1596-1603.

11. Christensen, N. J., and J. Iversen. 1973. Release of large amounts of noradrenaline from the isolated perfused canine pancreas during glucose deprivation. Diabetologia. 9:396-399.

12. Walter, R., R. Dudl, J. Palmer, and J. Ensinck. 1974. The effect of adrenergic blockade in the glucagon responses to starvation and hypoglycemia in man. J. Clin. Invest. 54:1214-1220.
13. Grodsky, G. M., and R. E. Fanska. 1975. The in vitro perfused pancreas. Methods Enzymol. 39:364-372.

14. Herbert, V., K. S. Lau, C. W. Gottlieb, and S. J. Bleicher. 1965. Coated charcoal immunoassay of insulin. J. Clin. Endocrinol. Metab. 25:1375-1384.

15. Yalow, R. S., and S. A. Berson. 1960. Immunoassay of endogenous plasma insulin in man. J. Clin. Invest. 39:1157-1175.

16. Harris, V., G. R. Faloona, and R. H. Unger. 1979. Glucagon. In Methods of Hormone Radioimmunoassay. B. M. Jaffe and H. R. Behrman, editors. Academic Press, New York. 643-656.

17. Vasquez, B., V. Harris, and R. H. Unger. 1982. Extraction of somatostatin from human plasma on octadecylsilyl slica. J. Clin. Endocrinol. Metab. 55:807-809.

18. Refshauge, C. J., P. T. Kissinger, R. Dreiling, L. Blank, R. Freeman, and R. N. Adams. 1974. New high performance liquid chromatographic analysis of catecholamines. Life Sci. 14:311-322.

19. Caro, L. G., and R. P. van Tubergen. 1962. High resolution autoradiography. I. Methods. J. Cell Biol. 15:173-188.

20. Baetens, D., F. Malaisse-Lagae, A. Perrelet, and L. Orci. 1979. Endocrine pancreas: Three-dimensional reconstruction shows two types of islets of Langerhans. Science (Wash. DC). 206:1323-1324.

21. George, D. T., and P. T. Bailey. 1978. The effect of adrenergic and ganglionic blockers upon the L-dopa-stimulated release of glucagon in the rat. Proc. Soc. Exp. Biol. Med. 157:1-4.

22. Cegrell, L. 1968. The occurrence of biogenic monoamines in the mammalian endocrine pancreas. Acta Physiol. Scand. Suppl. 314:1-60.

23. Gerich, J. E., M. Lorenzi, E. Tsalikian, and J. H. Karam. 1976. Studies on the mechanism of epinephrine-induced hyperglycemia in man. Diabetes. 25:65-71.

24. Samols, E., and G. C. Weir. 1979. Adrenergic modulation of pancreatic A, B and D cells. $\alpha$-adrenergic suppression and $\beta$-adrenergic stimulation of somatostatin secretion, $\alpha$-adrenergic stimulation of glucagon secretion in the perfused dog pancreas. J. Clin. Invest. 63:230-238.

25. Johnson, D. G., and J. W. Ensinck. 1976. Stimulation of glucagon secretion by scorpion toxin in the perfused rat pancreas. Diabetes. 25:645-649.

26. Harvey, W. D., G. R. Faloona, and R. H. Unger. 1974. The effect of adrenergic blockade on exercise-induced hyperglucagonemia. Endocrinology. 94:1254-1258.

27. Bloom, S., A. Edwards, and N. Vaughn. 1974. The role of the autonomic innervation in the control of glucagon release during hypoglycemia in the calf. $J$. Physiol. 236:611-623.

28. Palmer, J. P., D. P. Henry, J. W. Benson, D. G. Johnson, and J. W. Ensinck. 1976. Glucagon response to hypoglycemia in sympathectomized man. J. Clin. Invest. 57:522-525.

29. Malik, K. U., and J. C. McGiff. 1974. Relationship of glucose metabolism to adrenergic transmission in rat mesenteric arteries. Circ. Res. 35:553-574.

30. Baum, D., D. Porte, Jr., and J. Ensinck. 1979. Hyperglucagonemia and $\alpha$-adrenergic receptor in acute hypoxia. Am. J. Physiol. 237:E404-E408.

31. Gerich, J. E., M. Langlois, C. Noacco, J. Karam, and P. H. Forsham. 1973. Lack of glucagon response to hypoglycemia in diabetes: Evidence for an intrinsic pancreatic alpha cell defect. Science (Wash. DC). 182:171-173.

32. Boden, G., G. A. Reichard, Jr., R. D. Hoeldtke, I. Rezvani, and O. E. Owen. 1981. Severe insulin-induced hypoglycemia associated with deficiences in the release of counterregulatory hormones. $N$. Engl. J. Med. 305:1200-1205.

33. Bolli, G., P. De Feo, P. Compagnucci, M. G. Cartechini, G. Angeletti, F. Santeusanio, P. Brunetti, and J. E. Gerich. 1983. Abnormal glucose counterregulation in insulin-dependent diabetes mellitus: Interactions of anti-insulin antibodies and impaired glucagon and epinephrine secretion. Diabetes. 32:134-141. 